\title{
A FANTASIA DO REAL E A LUDICIDADE NO CONTEXTO DA EDUCAÇÃO INFANTIL: PRÁTICA E INTERLOCUÇÃO PROMISSORAS.
}

Denise Watanabe, Tony Aparecido Moreira, José Milton de Lima, Márcia Regina Canhoto de Lima.

Curso de licenciatura em Educação Física - Faculdade de Ciências e Tecnologia, UNESP - Campus de Presidente Prudente. Agencia Financiadora: Conselho Nacional de Desenvolvimento Científico e Tecnológico - (CNPq). Email: de.wtnb@gmail.com

\section{RESUMO}

Este artigo traz avanços de uma pesquisa realizada em uma Instituição de Educação Infantil - I e II e partiu do pressuposto inicial de que, durante intervenções em projetos de extensão, as crianças não conseguiam expressar a fantasia do real durante as brincadeiras eas professoras desconheciam sua real importância e significado. A partir desse diagnóstico, objetivou-se estimular e ampliar o repertório lúdico e imaginativo das crianças e dasprofessoras; dialogando com as mesmas na tentativa de evidenciar a importância de tais atividades no desenvolvimento pleno das crianças além de ouviras vozes infantis e refletir sobre o que pensam, sentem, gostam, brincam e expressam. Fundamentada na Sociologia da Infância, adotou-se a abordagem de natureza qualitativa e a metodologia da pesquisa-intervenção, como forma de reflexão entre teoria e prática, objetivando modificar a realidade. Os resultados consistiram em avanços na criatividade, na forma de se relacionar, expressar e maior participação nas atividades.

Palavras-chave: Sociologia da Infância, Imaginação, Brincadeira, Infância e Culturas da Infância.

\section{INTRODUÇÃO E OBJETIVOS}

O presente artigo intitulado "A Fantasia do Real e a Ludicidade no contexto da Educação Infantil: prática e interlocução promissoras" é o resultado de uma pesquisa realizada com alunos de uma instituição de Educação Infantil situada no interior do Estado de São Paulo, matriculados na Educação Infantil - Infantil I e II e que possui por objetos de estudo saberes referentes ao imaginário infantil com base teórica na Sociologia da Infância.

Sabe-se que a maior parte das escolas Educação de Infantil não priorizam a imaginação e a criatividade e, comumente, memorizar e prestar atenção constituem-se os modelos convencionais adotados no contexto escolar, priorizando mais recordar e escutar do que estimular a aprendizagem de forma criativa. Essas Instituições desconsideram ou desconhecem a importância da imaginação como possibilidade e "instrumento" de aprendizado, no qual a criança aprende sobre si mesma, sobre o outro e sobre o mundo em que vive.

Haja vista que a Educação Infantil, amparada no modelo tradicional, tornou-se alvo de críticas de estudiosos e pesquisadores da infância. Muitas vezes, esses locais se restringem apenas a um lugar de preparação e antecipação para o futuro; de alfabetização quase exclusiva da 
linguagem oral, escrita e matemática; de verticalização do poder entre professores e crianças (no qual o professor fala e o aluno só escuta ou obedece) ou um lugar de reprodução mecânica dos conteúdos, muitas vezes entendidos como "sem sentido" pelos alunos. Mesmo no âmbito da Educação Infantil, materiais apostilados padronizam o processo de ensino-aprendizagem.

O que não se pode (e nem se deve) negar é a importância da escola como espaço de "possibilidades", local em que se fomentam as relações sociais e culturais, de pares, de brincadeiras (mesmo que, muitas vezes apenas casual e na hora do intervalo), de troca de experiências e de aprendizagens, nos quais, as crianças devem ser reconhecidas pelas Instituições e pelos adultos não como "vir a ser", mas protagonistas, atores sociais, sujeitos singulares, que possuem especificidades e particularidades, que necessitam além de cuidado e proteção, serem amadas, ouvidas e respeitadas!

Diversas áreas do conhecimento e concepções permearam a história infantil. Teorias como "tabula rasa", "adulto em miniatura", "receptáculo passivo de informações", "vir a ser", de "desenvolvimento natural" ou somente "biológico" e da Sociologia tradicional influenciaram e continuam a influenciar muitos conceitos sobre a criança e a infância.

Com uma nova perspectiva, a Sociologia da Infância buscou compreender a criança e a infância de forma diferente. Nela, a criança é reconhecida como "ator social, agente social ou protagonista" e a infância uma "categoria estrutural ou geracional". Sarmento (2003) foi o responsável por elaborar os quatro Eixos Estruturadores das Culturas da Infância: Interactividade, Ludicidade, Fantasia do Real e Reiteração que constituem representações particulares das formas infantis de se expressar, aprender, relacionar, imaginar, viver.

A imaginação é "[...] inerente ao processo de formação e desenvolvimento dapersonalidade e racionalidade de cada criança concreta" [...] que acontece "no contexto social e cultural que fornece as condições e possibilidades desse processo" (SARMENTO, 2003, p. 3). Evidencia de que, quanto maiores e mais significativas forem as influências e atividades com as crianças, maiores as chances de expandir a sua criatividade e imaginação. As práticas lúdicas e imaginativas possuem estreita relação entre si e dependemda intencionalidade, da ação educativa dos docentes e das Instituições de Educação Infantil.

A imaginaçãodeve ser estimulada através das brincadeiras. Através delas, é possível à criança imitar e representar papéis; (re) criar personagens da TV, da vida real ou fictícios; representar ou lidar com situações do cotidiano de difícil compreensão ou até mesmo dolorosas; 
transformar e representar objetos, animais; relacionar-se com seus pares, com os adultos, ou com o mundo à sua volta.

O Referencial Curricular Nacional da Educação Infantil - RCNEI (1998) aborda a magnitude do imaginar e do brincar, através de experiências que sejam significativas para a criança, colaborando para as relações sociais, afetivas, cognitivas e emocionais. Para Lima (2008):

Quando brinca ou joga, a criança transforma objetos, animais, pessoas, lugares, coordena diferentes experiências, através da memória e da imaginação. O momento de brincar pode ser visto como um laboratório, um espaço de experimentação, no qual a criança pode ensaiar, errar, sem a pressão do mundo adulto. A criança, por meio da linguagem simbólica, utiliza-se de objetos, insere-se no mundo da cultura, constrói o pensamento, lida com seus sentimentos e amplia suas relações sociais. (BRASIL, 1998b, p. 10-11 apud LIMA 2008 p. 14).

A Fantasia do Real possibilita àcriança transpor o mundo real de forma imaginativa, criar ou recriar situações vividas por ela no dia a dia. Uma forma encontrada pela criança para interpretar situações, imitar, criar e recriar personagens, objetos, ficar mais perto do super-herói da televisão ou de seu livro preferido; iniciar uma viagem fantástica; representar papeis, como quando brinca de casinha, imita e recria situações vistas por ela e que fazem parte do cotidiano de sua família.

A Ludicidade está intimamente ligada à imaginação e não são exclusividades infantis. Os adultos também possuem um vasto repertório lúdico e imaginativo, por vezes maior do que das crianças. Essa condição se deve às experiências vividas no mundo real, ou seja, como o adulto possui uma bagagem maior, mais condições e elementos ele tem para imaginar. O que diferencia a brincadeira de adultos e a das crianças, é que brincar para a criança é aquilo que ela faz de mais sério:

A ludicidade constitui um traço fundamental das culturas infantis. Brincar não é exclusivo das crianças, é próprio do homem e uma das suas atividades sociais mais significativas. Porém, as crianças brincam, continua e abnegadamente. Contrariamente aos adultos, entre brincar e fazer coisas sérias não há distinção, sendo o brincar muito do que as crianças trazem de mais sério. (SARMENTO 2004, p. 15)

A interactividade significa uma forma de a criança relacionar-se com seus pares e com o mundo à sua volta, através de familiares, amigos, professores, parentes, vizinhos entre outros. É possível à criança produzir cultura própria enquanto gradativamente participa da cultura adulta. Segundo Corsaro (2011, p. 53): 
Pela interação com colegas em grupos de amigos e da pré-escola, as crianças produzem a primeira de uma série de culturas de pares, na qual conhecimentos e práticas da infância são gradualmente transformados em conhecimentos e habilidades necessários para participar do mundo adulto. [...] a produção infantil de culturas de pares não é uma questão de simples imitação ou apropriação direta no mundo do adulto. As crianças se apropriam criativamente de informações do mundo adulto para produzir suas próprias culturas de pares. Tal apropriação é criativa no sentido de que estende e desenvolve a cultura de pares; as crianças transformam as informações do mundo adulto a fim de responder às preocupações de seu modo. Dessa forma, contribuem simultaneamente para a reprodução da cultura adulta. Assim, as culturas de pares infantis têm uma autonomia que as tornam dignas de documentação e estudo por si. P.53

A reiteração é um tempo recursivo, sem medidas, que pode ser sempre reiniciado ou repetido [...] "um tempo continuado onde é possível encontrar o nexo entre o passado da brincadeira que se repete e o futuro da descoberta que se incorpora de novo" (SARMENTO, 2004, p. 17). A reiteração permite à criança retomar a brincadeira ou a estória com a mesma intensidade do momento em que parou, e iniciar o "era uma vez" de novo e de novo.

Através da Sociologia da Infância, dos estudos sobre as crianças e a infância foi possível vivenciar a prática, criar vínculos com os sujeitos do contexto; conhecer os problemas da realidade e buscar embasamento para tentar superá-los ou amenizá-los; ampliar o repertório de brincadeiras e atividades lúdicas e imaginativas das professoras e das crianças, proporcionando atividades diversificadas e significativas, na tentativa de vencer a falta de sentido do estudo escolar e vencer a desvalorização da imaginação e da ludicidade.

\section{METODOLOGIA}

A presente pesquisa está amparada no Protocolo do Comitê de Ética em Pesquisa (CEP): Processo no 71/2009, da FCT/UNESP de Presidente Prudente.

A pesquisadora, além das intervenções na Instituição Escolar participa ativamente do Centro de Estudos e Pesquisa em Educação, Ludicidade, Infância e Juventude - CEPELIJ e do Grupo de Pesquisa: Cultura Corporal: Saberes e Fazeres, da FCT/UNESP - Campus de Presidente Prudente. De caráter qualitativo, a pesquisa respaldou-se na metodologia da intervenção como instrumento de investigação, ação e reflexão do contexto analisado. As experiências com os alunos consistiram em contar estórias e desenvolver jogos e brincadeiras que tivessem estreita relação com os roteiros narrados. As intervenções eram divididas em momentos, ou seja, seguia 
uma sequência, anteriormente pensada, mas não obrigatória. Buscamos uma metodologia baseada na escuta e nas falas infantis e não na visão adulta sobre a criança. Para Muller:

Todo pesquisador deve se inclinar sensivelmente para a arte de apreender a voz da criança na singularidade de suas tessituras, isto é, ouvir representa abrir mão de qualquer possibilidade de juízos e de valores que possam corromper a tonalidade do que é dito pela criança, não cedendo lugar à tentação de querer ouvir o que se pretende ouvir. $(2010$, p. 67)

A intervenção inicia-se na sala de aula (não obrigatoriamente) com as falas infantis. São feitas perguntas sobre os cotidianos, as brincadeiras favoritas, entre outros. Posteriormente, conta-se a estória, que pode acontecer com ajuda de recursos lúdicos. Dois personagens imaginários foram introduzidos: Lipe e Luci, os quais nunca tiveram as suas características descritas, para que as crianças os imaginassem livremente.

A próxima etapa consiste na brincadeira, hora de vivenciar as estórias, com os amigos reais e/ou imaginários. A intervenção finaliza-se através das falas infantis. Através desse diálogo e das anotações inseridas no diário de campo, coleta-se de dados, anotações e observações relevantes que revelam elementos da ludicidade, imaginação, destaque para a forma e o conteúdo usado pelos participantes da pesquisa e implicações das atividades no processo de aprendizagem e desenvolvimento em diversos aspectos: cognitivo, afetivo, social e motor. Quando necessário, utiliza-se outros recursos que auxiliam na coleta de dados, como fotos, gravações, etc.

\section{RESULTADOS}

Durante as intervenções, as crianças demonstraram gradativamente maior criatividade e participação efetiva nas atividades, evidenciando avanços na forma de se relacionar, comunicar e expressar. Algumas professoras relataram que durante os outros dias (em que não era da intervenção), as crianças expressavam seu desejo e contentamento de participar das atividades lúdico-imaginativas, assim como perguntavam se faltava muito para chegar o dia de vivências proporcionadas pela investigação escola, além de expressarem brincadeiras, estórias e músicas dadas nas intervenções anteriores.

Em uma das estórias havia um dragão que estava machucado e precisava de ajuda. Um aluno veio correndo e ao me abraçar disse:

- O dragão quer me pegar!

Outro aluno, durante o intervalo, me abordou e fez a seguinte pergunta:

- Você vai brincar com a outra turma? 
- Sim!

- E vai ter dragão?

- Sim! Eu acho que vai!

- Bem bravo?

- Sim, bem bravo!

- Eu vou matar o dragão!

Outro dado corresponde ao relato de outras professoras do contexto escolar (outras seriações) ao expressarem que:

-as intervenções deveriam englobar também as séries iniciais do ensino fundamental.

No final do ano de 2012, fui convidada para a formatura do pré II. No dia da cerimônia de formatura uma menina de aproximadamente 11 anos veio conversar comigo:

-Meu irmão sempre fala das brincadeiras que tem na escola de sexta feira (dia da intervenção). Às vezes, quando a minha família tem algum compromisso, como geralmente visitar a avó que está meio doente, e que meu irmão precisaria faltar na aula de sexta feira ele sempre dizia:

-Ah mãe, eu não posso faltar hoje! Hoje vai ter uma brincadeira superlegal na escola e eu não posso faltar!

-Ou se não, quando isso acontecia (de precisar faltar na aula de sexta) ele falava:

-Ah... A gente não pode ir na vó depois das seis da tarde (horário após as aulas)?

A irmã enfatizou que seu irmão gostava muito das brincadeiras e não gostava de faltar no dia em que havia as intervenções.

Em uma intervenção foram levados brinquedos para fazer "cantinhos" para brincar de cabeleireiro, oficina mecânica, etc., uma aluna pegou uma chapinha, secador e começou a interagir alegremente com a colaboradora. Ela, então, pegou uma boneca, "bateu" nela e falou:

- Quando eu "to" trabalhando ela não fica quieta!

Ela continuou, então, a brincar alegremente com outras crianças de cabeleireiro. Rodari (1982, p. 104) explica sobre esse tipo de brincadeira:

A menina que brinca com suas bonecas e, enfim, com o seu riquíssimo enxoval, móveis, utensílios, pratinhos, xícaras, eletrodomésticos, casas e cidades em miniatura reproduz no jogo todo seu conhecimento da vida doméstica, exercita a manipulação dos objetos, compondo-os e recompondo-os, designando-lhes um espaço e um papel; mas ao mesmo tempo as bonecas lhe são úteis para dramatizar suas próprias relações, e eventualmente seus conflitos. Grita com a boneca usando as mesmas palavras gritadas pela mãe, para descarregar cada sentimento de culpa. 
Acaricia e afaga as bonecas para exprimir sua necessidade de afeto. Pode escolher uma delas para amar e odiar de modo especial, caso a boneca lembre o irmãozinho do qual tem ciúme.

Durante uma brincadeira em que simulávamos que as crianças eram meio de transportes, uma das crianças, após se divertir muito com as outras, vai até sua professora de sala e expande sua imaginação:

-Prô, tem que abastecer o carro no posto!

Em outra sala, com a mesma brincadeira, as crianças estavam correndo muito rápido. $\mathrm{O}$ colaborador mostrou, então, uma placa vermelha, que significava que elas deveriam parar. Expliquei que elas estavam correndo demais, por isso foi levantado à placa de "pare". Uma das crianças, então perguntou:

-Tem radar?

Na fala dessas crianças é possível perceber que elas expressam algo que ouviram ou vivenciaram no cotidiano delas, mas que (re) significaram ou (re) interpretaram criativamente durante o momento de brincar.

\section{DISCUSSÕES}

A brincadeira imaginativa é uma forma de representação do mundo real. Mais do que isso, é um modo de inteligibilidade, de estabelecer relações, de criar e (re) inventar. Nelas as crianças repetem e recriam rotinas a que estão acostumadas, mais do que isso, não apenas reproduzem, mas, elaboram novas estórias, diferentes formas de brincar, de se apropriar e produzir cultura.

Através do diálogo constante com as professoras foi perceptível mudanças em suas concepções sobre as brincadeiras. Foi aplicado um questionário (não era necessário se identificar). Ao perguntar se "As brincadeiras desenvolvidas pelo projeto eram realizadas durante a semana?", todas as professoras afirmaram que "sim". Ao perguntar se o projeto auxiliou e modificou a prática e as concepções das professoras, elas responderam afirmativamente:

- Os alunos da UNESP são fantásticos eles desenvolveram um trabalho riquíssimo e de qualidade, quando desenvolvia a prática pedagógica os alunos ficavam encantados e participavam das atividades com alegria e entusiasmo.

- Como eu curso pedagogia sempre faço uma reflexão sobre a minha prática pedagógica. $O$ projeto me ajudou a pensar como mudar a prática em cima das novas reflexões.

\section{CONCLUSÕES}


As intervenções escolares, os grupos de estudos e de pesquisas contribuíram imensuravelmente para a formação, o conhecimento e aprofundamento teórico e prático, possibilitando a formação continuada das professoras envolvidas no processo e, principalmente proporcionar um rol de atividades diversificadas para o aprendizado infantil, que contribuísse e expandisse as capacidades imaginativas, criativas, cognitivas das crianças, de relações sociais e de pares. As educadoras, no decorrer do projeto, expressaram melhor compreensão no que se referia à importância das brincadeiras na vida das crianças:

- O projeto realizado pelos alunos é de extrema importância para os alunos e professores, levando-os ao imaginário e a realidade de cada um, agradeço a todos eles por participar juntamente nesta escola este trabalho maravilhoso.

As crianças mostraram-se mais criativas, participativas e expressivas. Elas relataram personagens fictícios; situações vivenciadas ou vistas no cotidiano e (re) inventadas durante as brincadeiras; assim como expressaram desejo de participar das atividades, reivindicadas durante sua permanência no âmbito familiar. Continuaremos a aprofundar os estudos teóricos numa tentativa de estreitá-los com a prática, buscando o respeito e a valorização das especificidades e necessidades das crianças e da infância.

\section{REFERÊNCIAS}

BRASIL. Ministério da Educação e do desporto. Referencial Curricular Nacional de Educação Infantil: introdução. Brasília: MEC/SEF, v.1, 1998.

CORSARO, W. Sociologia da Infância. Porto Alegre: Artmed, 2011.

LIMA, J. M. O jogo como recurso pedagógico no contexto educacional. São Paulo: Cultura acadêmica: $2008.157 p$.

MULLER, F.. Infância em perspectiva: políticas, pesquisas e instituições. São Paulo: Cortez, 2010. $255 \mathrm{p}$.

RODARI, G. Gramática da fantasia. São Paulo: Summus, 1982.

SARMENTO, M. J.. As culturas da infância nas encruzilhadas da 2a modernidade. Braga: Instituto de Estudos da Criança, Universidade do Minho, 2003. (texto digitado).

Imaginário e culturas da infância. Cadernos de Educação, Pelotas, v. 12, n. 21, p. 51-

69, 2003. 
Encontro de Ensino, Pesquisa e Extensão, Presidente Prudente, 21 a 24 de outubro, 2013

SARMENTO, M. J.; CERISARA, A. B. Crianças e miúdos: perspectivas sociopedagogicas da infância e educação. Porto: ASA, 2004. 